to save life or prevent a deterioration in the patient's health without formal consent. Medical and not lega considerations are of greater importance in lifethreatening situations and the courts are most unlikely to censure a practitioner for proceeding to provide essential treatment in an emergency. ... The guiding principle is to act in good faith and in the immediate best interests of the patient's health and safety. If there is any doubt there should be no hesitation in seeking the advice and opinion of one or more colleagues.

The legal arguments used in the recent court cases to which Peckham refers do not seem to be directly relevant to the emergency treatment of life threatening drug overdoses. ${ }^{34}$ In the current legal climate, it is suggested that the risk of treating such patients and being charged with assault is less than the risk of facing charges of medical negligence from the patient's family if treatment is withheld and the patient dies.

As a psychiatric registrar, I have been contacted on several occasions by medical staff who are uncertain of the circumstances in which common law and the Mental Health Act can be applied. The first aim must be to avoid using such powers by persuading patients to accept treatment voluntarily. If the patient continues to refuse treatment however, common law allows the practitioner all necessary powers to detain and treat patients in life threatening medical emergencies.

The Mental Health Act is for the treatment of mental disorders 5 and cannot be extended to the treatment of medical emergencies even if they arise as a direct consequence of a mental disorder. If patient is mentally ill and takes a life threatening drug overdose the first priority is for the medica emergency to be treated, if necessary under common law. The need for psychiatric treatment can be assessed after medical treatment has been completed.

BRIAN DALAL

Department of Psychiatry,

University Hospital,

Queen's Medical Centre

Nottingham NG7 2UH

I Peckham D. Emergency treatment against a patient's wishes. $B M 7$ 1992;305:478-9. (22 August.)

Palmer RN. Consent and confidentiality. London: Medica Protection Society, 1991. (Also published in: Jackson JP, ed. A Protection Society, 1991. (Also published in: Jackson JP, ed.A practical guide to medicin

3 Dyer C. Court says doctors were right to treat Jehovah's Witness. BMF 1992;305:272. (1 August.) 4 Dyer C. 16 year old's refusal of treatment overruled. $B M \mathcal{J}$
1992;305:76. (11 July.)

5 Mental Health Act 1983. London: HMSO, 1983.

\section{Eradication of poliomyelitis}

EDITOR,-Andrew J Hall's editorial points to three elements in the eradication of poliomyelitis namely, immunisation days, mopping up operations, and high quality surveillance - and rightly recommends the availability of laboratory support.

For global eradication of poliomyelitis two tie laboratory support would be essential to carry out at least in industrialised countries, investigations like the in situ polymerase chain reaction ${ }^{2}$ or in situ transcription ${ }^{3}$ to identify and characterise poliovirus genomes both in clinical specimens and in postmortem material from suspected cases. The developing countries where poliomyelitis is hyperendemic would require simplified, one or two step test procedures that did not depend on tissue cultures to measure poliovirus antibody levels and screen for polioviruses in clinical specimens. That should not be an insurmountable technological issue if rapid diagnostic techniques like liposome immunoassays were to be adapted to polioviruses Liposome immunoassays, which use antibodie conjugated to liposomes (artificial phospholipids) containing a dye (rhodamine sulphate), are available for detecting antigens in clinical specimens. They do not require a solid phase for the antibodyconjugate to generate a signal since the signal is generated by release of rhodamine sulphate dye during the antigen-antibody reaction.

No apparent source of poliovirus infection was established in three of the cases reported by Rachel Joce and colleagues. ${ }^{5}$ Any possibility, albeit rare of reactivation of poliovirus in the host nervous system after its acquisition decades earlier merits exclusion. A study of the intrathecal immune response of 36 patients with the postpolio syndrome reported oligoclonal $\operatorname{IgM}$ bands in 31 patients, significantly raised cerebrospinal fluid levels of IL-2 and s-IL-2R, and a correlation between intrathecal synthesis of IgM antibody synthesis and the cerebrospinal fluid IL-2 and s-IL-2R levels. ${ }^{6}$ Postmortem tissue from the 41 year old man reported on by Joce and colleagues could be subjected to an in situ polymerase chain reaction with poliovirus specific primers.

The acquisition of poliomyelitis by a 62 year old previously healthy man during a holiday in a beach resort in Morocco $^{5}$ is similar to a case in a 65 year old man with type 1 poliovirus in Morocco itself. Indeed, both these cases are a grim reminder of the continuing rise in the number of tritypic antibody negative people among those aged 50 and over in industrialised countries. As polio vaccine was not available before the 1950 s people now aged over 50 would not have been routinely vaccinated. ${ }^{9} \mathrm{~A}$ simplified test procedure to screen such people for antibodies to poliovirus would be invaluable. Regular screening of travellers to endemic areas would ensure that otherwise healthy people in this age group were adequately vaccinated against polio before departure. Furthermore, such screening would also ensure that there were not any tritypic antibody negative people and that the possibility of an outbreak of polio was minimal.

SUBHASH C ARYA

Centre for Logistical Research and Innovation,

M-122 (of part 2), Greater Kailash-II,

New Delhi-110048,

India

1 Hall AJ. Polio eradication as 2000 approaches. BMf 1992;305: 69-70. (11 July.)

2 Bagasra O, Hauptman SP, Lischner HW, Sachs M, Pomerantz RJ. Detection of human immunodeficiency virus type 1 provirus in mononuclear cells by in situ polymerase chain provirus in mononuclear cells by in situ
reaction. $N$ Engl f Med 1992;326:1385-91.

3 Carstens JM, Tracy S, Chapman NM, Gauntt CJ. Detection of enteroviruses in cell cultures by using in situ transcription. f Clin Microbiol 1992;30:25-35.

4 Gerber MA. Randolph MF, DeMeo KK. Liposome immunoassay for rapid identification of group A streptococci directly rom throat swabs. 7 Clin Microbiol 1990;28:1463-4.

5 Joce R, Wood D, Brown D, Begg N. Paralytic poliomyelitis in England and Wales, 1985-91. BMF 1992;305:79-82. (11 July.) 6 Sharief MK, Hentges R, Ciardi M. Intrathecal immune response in patients with post-polio syndrome. $N$ Engl f Med 1991;325:749-55.

7 Yang C-F, De L, Holloway BP, Pallansch MA, Kew OM. Detection and identification of vaccine-related polioviruses by the polymerase chain reaction. Virus Res 1991;20:159-79.

8 Ellis CJ, Telfer P, Lawton NF. Poliomyelitis in the UK. Lance 1990;335:364.

9 Arya SC. Poliomyelitis serosurveillance and immunization for elderly people in otherwise efficiently immunized areas. Vaccine 1990;8:514

\section{Nurses' access to subjects for research}

EDITOR, - I would like, through your column, to raise a serious concern in relation to nurses' access to patients for their inclusion in nursing research. It has often been drawn to my attention that nurses have been required by local ethics committees to seek access to patients through their medical colleagues even though the studies related directly to nursing matters. Occasionally such access has been refused even when ethical approval has been given.

This raises several questions. Firstly, it would seem that it is the patients themselves who should be offered the opportunity to decide whether or not they wish to participate in nursing research, provided that they are fully informed of the nature of the study. It has been the custom to admit patients to hospital under the care of a named medical consultant, or to access community care through a general practitioners' register, but this does not imply that patients should be denied the right to make personal decisions about their involvement in research. Protecting them by denying them such choice does not seem to be in line with an acknowledgment of their right to choose.

Secondly, there is an important question about whether one professional group has the right to gatekeep research activities initiated by colleagues working in a complementary but different profession. While multidisciplinary work will always have a vital role to play there is also an urgent need for each profession to deepen its own understanding of practice. Without the opportunity to explore nursing matters through rigorous, well controlled research our understanding of the contribution that nurses and nursing can make to health care would be severely hampered. It is both worrying and sad that nurses could be restricted in this activity by colleagues who are not always familiar with either the areas of work which they would like to explore or the methods which they may employ.

I would be interested to hear how widespread this practice is and the rationale for such action.

BARBARA VAUGHAN

Programme Director,

Nursing Developments,

King's Fund Centre,

London NW1 7NF

\section{Congenital toxoplasmosis}

EDIToR,-Susan Hall's review article stated that those in favour of screening for toxoplasmosis "have held the limelight." This is odd as her article, a recent editorial,, and a report from a multidisciplinary working group set up by the Royal College of Obstetricians and Gynaecologists $^{3}$ have all been against screening. Unfortunately, the thinking in these publications is inconclusive: there is not enough information, so we do nothing. Our approach is that if there is not enough information, this information should be obtained. ${ }^{4}$ We first made this suggestion in January 1990. A problem has been identified and an obvious solution is available, ${ }^{4}$ yet we wait

We have reviewed published epidemiological information, including our study over 10 years in which 16000 women were prospectively screened. We have dealt with false positive results and their reduction at least a hundredfold, and emphasised the importance of counselling. ${ }^{4}$ Our position is that studies such as ours cannot yield more information. An acceptable study should be dealing with 50000 pregnancies a year, so a multicentre trial may be more appropriate than smallscale studies. The review article may have been unable to prove the case for a national screening programme, but it clearly shows the need for a government funded pilot screening programme. ${ }^{4}$ Our position is therefore that there is not enough information for national screening, but a pilot programme should be instigated now.

The difference between actively seeking information as opposed to analysing available data is seen in the British Paediatric Surveillance Study. Fourteen cases a year may be substantially less than the expected number but is more than twice the incidence previously calculated by Susan Hall in 1983. ${ }^{5}$ Her previous figure was from analysis of laboratory reports, and the current figure is also from clinicians dealing with the problem

As professionals deliberate and multidisciplinary bodies produce reports, life goes on. Many women are now demanding to be tested, and one medical defence organisation has advised members that they may face litigation if they refuse to screen such women. ${ }^{4}$ Patients are now expected to be seen 
within 30 minutes of an outpatient appointment How long should they wait for the professionals to offer a solution rather than restate the problem?

D O HO-YEN

A W L JOSS

J M W CHATTERTON

Scottish Toxoplasma Reference Laboratory,

Raigmore Hospital,

Raigmore Hospital

I Hall SM. Congenital toxoplasmosis. BMf 1992;305:291-7. (1 August.)

2 Antenatal screening for toxoplasmosis in the UK [editorial]. Lancet 1990;336:346-8.

3 Multidisciplinary Working Group. Prenatal screening for toxoplasmosis in the UK. London: Royal College of Obstetricians and Gynaecologists, 1992.

4 Ho-Yen DO, Joss AWL, eds. Human toxoplasmosis. Oxford: Oxford University Press, 1992.

5 Hall SM. Congenital toxoplasmosis in England, Wales, and Northern Ireland: some epidemiological problems. $B M \mathcal{J}$ 1983;287:453-5.

\section{Contact tracing in HIV infection}

Editor,-R A Keenlyside and colleagues' questionnaire on genitourinary physicians' and health advisers' attitudes to notifying partners of people with HIV infection raises some interesting points with respect to public education, contact tracing, and perception of risk activities with regard to transmission of HIV.' Altogether $91 \%$ of the physicians and health advisers did not believe that the media adequately informed the general public about their risk of HIV infection. A case at this hospital recently highlighted this point.

A 36 year old homosexual man was admitted as an emergency with pneumocystis pneumonia. He had had a monogamous relationship for the past six years and did not believe that he was at risk of HIV infection. He had practised unprotected anal intercourse with his partner and did not perceive this as a risk factor for transmission of HIV. His partner, who, after counselling, consented to HIV antibody testing and was found to be HIV positive, was unaware of their risk as he did not realise that they could have acquired the infection more than six years before. Both had been sexually promiscuous before this relationship.

Because resources for education about AIDS are limited the question arises as to who should be targeted. As yet a reliable method of measuring the outcome of such education does not exist, and we think that public education campaigns would be better targeted more intensively at people at risk. We strongly support the recommendation that there should be national guidelines for notifying partners of people with HIV infection, especially when the contacts may be unaware of their exposure and risk. Tracing contacts and notifying partners is effective in controlling other sexually transmitted diseases, ${ }^{2}$ and practice with regard to HIV infection should be reviewed.

A WARDROPPER E L C ONG

Newcastle General Hospital

Newcastle upon Tyne NE4 6BE

1 Keenlyside RA, Hawkins AS, Johnson AM, Adler MW. Attitudes to tracing and notifying contacts of people with HIV infection. BMF 1992;305:165-8. (18 July.)

2 Health Education Council. A handbook on contact tracing in sexually transmitted diseases. London: Health Education Council, 1980.

\section{Vocational training and maternity benefits}

EDITOR,-We wish to bring to readers' attention the situation regarding maternity benefits for junior doctors who are doing, or have finished, vocational training. At present no maternity leave is given if the doctor has finished the scheme and has not yet entered a partnership. Frequently women find themselves doing locum work before entering a partnership. Even if, as is the case for one of us, they have done locum work consistently for at least two years no benefit is payable. Also, any work they have done in the NHS since qualification-anything up to six years or so-is not taken into consideration.

We know that many women have found themselves in this situation, having worked full time through their vocational training and then having children before taking up a partnership. We would like to get in touch with these women and would value suggestions as to how this injustice may be rectified. Women who have been in continuous employment, usually for two years, in other spheres of employment are entitled to full benefits. We believe that something must be done.

RACHEL ARNOLD MIRIAM BROWN

Sheffield S6 3GQ

\section{Confidential illustrations}

EDITOR,-Journals seem to be publishing an increasing number of articles whose illustrations inadvertently include confidential details on patients. ${ }^{1-3}$ The problem arises with ultrasound scans, computed tomograms, magnetic resonance images, and so on, where the patient's name, date of birth, hospital number, and date of examination are incorporated in the films. I'm pleased to say that I have not yet come across such an incident in the $B M \mathcal{F}$, but authors, departments of medical illustration, and editors should be sensitive to this and remember to delete the details on patients.

D CLEMENTS

Llandough Hospital,

Penarth,

South Glamorgan CF6 1XX

1 Burgess NA. Pyodema gangrenosum with large circumferential perianal skin loss in a child. Brf Clin Pract 1991;45:223-4.

2 Pinn S. A facial root is mapped out for cranial tumours. Hospital Doctor 1992; May 14:46.

3 Iro H, Schneider HT, Fodra C, Waitz G, Mitsche N, Heinritz $\mathrm{HH}$, et al. Shock wave lithotrypsy of salivary duct stones. Lancet 1992;339:1333-6.

${ }_{*}^{*}$ The $B M \mathcal{F}$ has already addressed this problem ${ }^{\prime}$ and conforms to guidelines issued by the International Committee of Medical Journal Editors on protecting patients' anonymity. ${ }^{2}$ Protecting anonymity is often more difficult in clinical photographs and case descriptions than in the images D Clements mentions: these can easily be anonymised by masking out the names and numbers. $-\mathrm{ED}$, $B M F$

1 Smith J. Keeping confidences in published papers. $B M F$ 1991;302:1168

2 International Committee of Medical Journal Editors. Protection of patient anonymity. BMF 1991;302:1194.

\section{Asian doctors and training in general practice}

EDITOR, - I was sad to read Raj Menon's confused letter on Asian doctors and training in general practice. ${ }^{\prime}$ Clearly, he does not know about the current state of vocational training and the rigorous selection procedures that potential trainers must undergo before approval.

For Menon's information, a potential trainer in Yorkshire is expected to attend trainers' workshops and half day release courses regularly during the year preceding his or her application and then to attend a two day residential assessment seminar followed by a searching interview by the appointment subcommittee of the regional postgraduate medical education committee for general practice. In addition, the potential trainer's practice, which receives a formal visit by representatives of the committee, must fully comply with the regiona criteria for approval, which are even more demanding than the national recommendations of the Join Committee on Training in General Practice. Even then, the appointment is for only a probationary period of one year, and the renewal of the appointment depends on a further visit to the practice and feedback from the course organisers and trainees in the practice. Furthermore, all trainers are expected to attend residential training seminars, at the rate of not less than one every two years.

Menon's claim that Asian doctors receive training only in poor training practices casts doubts on his appreciation of vocational training and it dynamic evolution over the past two decades. Furthermore, the assertion that overseas doctor are rejected as trainers is totally unrelated to the realities of the situation.

Regional Adviser in General Practice

JAMIE BAHRAMI

Department of Postgraduate Medical Education,

Leeds University,

Harrogate HG1 $5 \mathrm{AH}$

1 Menon R. Asian doctors and the MRCGP examination. BMf 1992;305:368. (8 August.

\section{Advice on health care workers infected with HIV}

EDITOR,- On two occasions consultants in genitourinary medicine have sought my advice regarding the possibility of health care workers who are positive for HIV continuing to provide care for patients. In both cases the consultants are shouldering an unnecessary burden since the United Kingdom advisory panel for HIV infected health care workers was set up to give advice in cases such as these. Cases can be discussed without disclosure of the workers' identity, and the advice given can be used by the physicians as suggested by both the General Medical Council and the General Dental Council.

Information on the panel and other occupational guidance is contained in a booklet published by the Department of Health.

Special Needs Unit

Londons

Department of Health. AIDS - HIV infected health care workers. London: $\mathrm{DoH}, 1991$

\section{Irradiation of assistants' hands}

EDIToR,-Colin R Paterson and colleagues' lesson of the week on testing for congenital dislocation of the hip in children with osteogenesis imperfecta illustrates an equally important second lesson, which the authors fail to refer to. ${ }^{1}$ The radiograph of the infant's femoral fractures shows clearly the assistant's unprotected hands.

The National Radiological Protection Board and the Royal College of Radiologists are concerned about patients' exposure to unnecessary radiation. ${ }^{23}$ Unnecessary irradiation of assistants' hands while they immobilise children must be avoided. Numerous cheap immobilisation devices are available, and assistants must wear lead gloves. ANNE S HOLLMAN

X Ray Department,

Royal Hospital for Sick Children

Glasgow G3 8SJ

1 Paterson CR, Beal RJ, Dent JA. Osteogenesis imperfecta: fractures of the femur when testing for congenital dislocation of tractures of the femur when testing for congenit

2 National Radiological Protection Board. Patient dose reduction in diagnostic rudiology. Lud

diagnostic radiology. London: HMSO, 1990.
Harding LK. POPUMET, ionising radiation regulations. $\mathcal{F} R$ Coll Phys Lond 1991;25:280-1. 